\title{
CALEF- \\ DOSCOPIO \\ Raíces, vínculos y desafíos de la hermenéutica analógica
}

JULIO - DICIEMBRE 2007

Mauricio Beuchot, Lineamientos de la hermenéutica analógica, Consejo para la Cultura y las Artes (Colección: Ideas mexicanas), Nuevo León, México, 2006, 143 pp.

El trabajo filosófico se ha planteado preguntas muy diversas sobre la constitución del mundo hasta las diferentes cuestiones que el ser humano se plantea sobre sí mismo. El sentimiento de extrañeza y de temor que el hombre ha experimentado frente a la naturaleza es uno de los elementos que origina la búsqueda del conocimiento. El ser humano ha forjado explicaciones que van desde el antiguo mito hasta las teorías más contemporáneas. Trata, de esta manera, de satisfacer su curiosidad y resolver los problemas que práctica y teóricamente se la han presentado en su existencia. De tal forma, que podemos constatar que el conocimiento avanza a la par del desarrollo humano y como producto del mismo.

Por medio del lenguaje nos es posible conceptualizar el mundo y, con esto, conocerlo, este conocimiento se extiende a la otredad y nos permite conocer al otro análogo a mi, otro yo que, sin embargo, no conozco con profundidad, pues su mente y lo contenido en ella me es proporcionado y mediado a través del lenguaje. De la misma forma, todas las explicaciones y teorías acerca del mundo están conformadas por ideas que se expresan a través del lenguaje, mismas que tienden a su objetivación y con ello a la universalidad. Aunque, como sabemos, no siempre el lenguaje alcanza esa claridad y coherencia en su expresión. 
Muy a pesar de las incontables pretensiones de universalidad y por tanto de univocidad, la necesidad de un elemento interpretativo aparece en toda experiencia humana. La hermenéutica es el elemento mediador necesario que parte de la consciencia de cierta inmanencia del lenguaje con respecto a la realidad con la intencionalidad de recuperar el sentido que está presente en algún texto.

En el libro Lineamientos de hermenéutica analógica, el pensador mexicano Mauricio Beuchot nos presenta la estructura y función de una hermenéutica, no sólo como una teoría interpretativa, sino como una propuesta mediadora que supera las aporías de la modernidad, que nos hace consciente de la imposibilidad de la univocidad; y que nos enfrenta críticamente a la posmodernidad y a la apertura infinita de interpretaciones que ésta produce.

En algunos capítulos del texto, Beuchot explica de manera sucinta la estructura, función y aplicaciones de la hermenéutica analógica. El autor parte de una noción general de Hermenéutica, presenta a la analogía en sus rasgos de proporcionalidad, lo que hace posible la mediación y el establecimiento de un orden jerárquico de interpretaciones.

El doctor Beuchot profundiza en el significado de la hermenéutica como la disciplina de la interpretación de textos. Señala que para la comprensión de un texto es necesario la contextuación del mismo y, asimismo, advierte que este trabajo implica necesariamente una autointerpretación. Varios autores señalan el carácter mediador que implica la interpretación: la abducción en Pierce; la construcción de proyectos en Gadamer e incluso la falsación de hipótesis en Popper, son teorías que de acuerdo con el autor presentan, en este carácter mediador, una noción prudencial por medio de la cual se van seleccionando las hipótesis en función de la virtud y la verdad.

Una vez señalada una noción general de la hermenéutica, el autor recurre a la analogía como órgano de vertebración de su propuesta. Esta categoría presenta una cara relacionada con la semejanza, sin que por ello se reduzca a ésta, y otra, en la que predomina la diferencia. Analogía es un medio de significación entre lo unívoco y lo equívoco. El primero es restrictivo e implica una igualdad de identidades, el segundo desata una inconmensurabilidad incontrolable, lo análogo presenta una 
parte idéntica y una parte diferente, proliferando ésta última, pues la semejanza se nos otorga en la experiencia humana misma.

La intencionalidad mediadora es el vértice de la estructura en la Hermenéutica analógica pues es a partir esta integración que se obtiene como resultado una ampliación limitada de la univocidad que es frenada por el rigor y evita la confusa equivocidad. Como un elemento constantemente mediador, la Hermenéutica analógica se hace presente entre el diálogo externo y el personal y reflexivo. Esta propuesta pretende la superación de las dicotomías en los problemas filosóficos, incluso aquellas que presentan por un lado la valoración y por el otro la descripción, pues de acuerdo con Beuchot, cada enunciado descriptivo conlleva en sí mismo elementos de suyo valorativos. La función característica de la Hermenéutica analógica es privilegiar la diferencia. Por medio de la analogía se nos proporciona a la finita comprensión humana un punto intermedio mediado por el diálogo, en el que predomina la diferencia sin negar la posibilidad de alcanzar algo de identidad.

A partir de las características señaladas de la Hermenéutica analógica, se desprende la facti- bilidad de aplicarla en distintos ámbitos, no sólo en el filosófico, sino en diferentes problemáticas y experiencias humanas en las que sea necesario un carácter interpretativo. Una de los áreas en los que esta teoría puede ser usada es, por ejemplo, la pedagogía, otra es el derecho, la historia del arte, la antropología, los estudios de género e incluso en la ingeniería sistemática.

Otro de las rasgos relevantes del libro que comentamos es la inclusión y el diálogo con filósofos de diferentes latitudes y épocas que han influido en la propuesta hermenéutica de Beuchot.

Históricamente la analogía es rastreada desde los pitagóricos, de los cuales pasó a Platón quien la veía como un equilibrio de vida. Aristóteles le agrega a la analogía un aspecto de atribución. En la edad media, la analogía encuentra un expositor en santo Tomás de Aquino, quien la usa en el mismo sentido que Aristóteles. En la modernidad se da un decaimiento de la analogía, encontrando sin embargo autores que la rescatan como Pascal y Kant. Posteriormente aparece en el pensamiento trágico de Nietzsche y en los trabajos de Pierce.

En nuestros territorios, en tiempos del descubrimiento del
C
A
E
D
O
$S C$
C
$P$
O 
nuevo mundo y de la conquista, es por la analogía que surge la comprensión entre dos mundos que se confrontan por vez primera: "... la utilización de la analogía impide ver al otro como meramente conquistable y destruible; hace que lo vea como prójimo"'. Presente en el barroco mexicano, para el siglo XVII, la analogía se presenta como sensibilidad hacía lo simbólico. El barroco en México es en sí mismo un movimiento netamente mestizo pues no es la representación de aquella cultura que vino desde España ni la cultura surgida en la propia tierra, sino una fusión de ambas culturas. En la época contemporánea latinoamericana, la analogía está presente en el pensamiento de Octavio Paz quien pone como centro de su poesía a la analogía misma, supeditando a ésta tanto la metáfora como la metonimia.

En filosofía de la historia, a partir de un análisis que hace Blumenberg respecto a la categoría de secularización como fundamento de la modernidad, Beuchot extrae un uso analógico que ha influido en su propia reflexión. La modernidad como tal es vista como la época de la libertad y el progreso, sin embargo, de acuerdo con el pensador mexicano, la visión progresista disuelve al individuo libre en la masa, restándole responsabilidad histórica. La modernidad pretende el goce de los privilegios y el uso de categorías que el cristianismo poseía pero por medios distintos. De este modo se puede ver que la modernidad está anclada en la tradición y no es sólo progreso e innovación. Hay en los trabajos de Blumenberg una unión de la filosofía de la historia con la analogía misma.

Para finalizar con el conjunto de autores en los que Beuchot encuentra un carácter analógico, señalaremos al filósofo argentino-mexicano Enrique Dussel. El concepto clave en su pensamiento es la analéctica, la cual consiste en el uso de la analogía dinamizada por el uso de la dialéctica, beneficio mutuo que obtienen tanto la dialéctica como la analogía. "...es la negación de la negación, la superación de la negatividad". ${ }^{2}$ Una propuesta

$2 \quad$ Ibid., p. 192
Mauricio Beuchot, Lineamientos de hermenéutica analógica, p. 45. 
que se presenta como crítica a la modernidad pero que no se reduce sólo a esto. Se trata de un movimiento transmoderno que extiende su crítica, más allá de la modernidad, al eurocentrismo y propone diferentes soluciones a la marginación que viven los marginados.

En muchos sentidos podría llegar a considerarse a la Hermenéutica analógica como una objetivación de la equivocidad, e incluso la legitimación de la multiplicidad de interpretaciones. Más que una objetivación, la analogía es una luz parpadeante de esa consciencia que se objetiva en la experiencia misma, de que la comprensión total nos es imposible, pero al comprender que no nos comprendemos del todo, nuestra comprensión se torna más profunda, permitiéndole dirigirse a donde le sea posible entablar una interpretación, nunca completa, pero si consciente de los límites de su aplicación. La Hermenéutica analógica mues- tra que la equivocidad nos lleva a una aporía tan absurda incluso como la univocidad y universalidad mismas, ya que la experiencia nos muestra de forma diáfana su imposibilidad. Sin embargo, la ampliación y el rigor de la interpretación se ha posibilitado a través de compartir, en un determinado horizonte histórico, con nuestros análogos y extraños los resultados de nuestro amor por el conocimiento y la palabra.

Tenemos un nuevo texto en el que, más allá de la coincidencia que pueda existir con las ideas ahí planteadas, nos encontramos, por un lado, la importancia de apostar por una filosofía propia y, por otra, nos vemos envueltos en un ejercicio autocrítico en el que el autor, como buen filósofo, no se retrotrae ante las dificultades de una hermenéutica analógica, de sus alcances y sus límites, sino que nos invita a colaborar en esta búsqueda tratando de probar los alcances de esta propuesta. 
